\title{
Impact of updating land surface data on micrometeorological weather simulations from the WRF model
}

\author{
S. M. KIRTHIGA and N. R. PATEL*
}

Indian Institute of Remote Sensing (IIRS), Dehradun - 248001, India

* Corresponding author; email: pnatoo@gmail.com

Received: November 20, 2017; accepted: January 22, 2018

\begin{abstract}
RESUMEN
Los procesos que ocurren en la superficie terrestre desempeñan un papel fundamental en el reparto de la energía superficial y la circulación atmosférica dentro de un sistema climático. La representación errónea del estado actual del suelo - en particular de aspectos espaciales específicos como cobertura del suelo, parámetros topográficos y biofísicos - contribuye a la incertidumbre en las simulaciones meteorológicas tanto a escala local como regional. El presente estudio analiza el impacto de los datos de superficie en el desempeño del modelo de investigación y pronóstico del tiempo (Weather Research and Forecasting, WRF) para realizar simulaciones micrometeorológicas/cercanas a la superficie, en particular de variables sensibles como temperatura, humedad relativa, radiación solar y velocidad del viento. La hipótesis es que las bases de datos de superficie actualizadas podrían ayudar a mejorar los pronósticos micrometeorológicos sobre el dominio que comprende a los estados de Punjab, Haryana y Uttarakhand en la India. Para inicializar el modelo se utilizan la base de datos de uso y cobertura del suelo derivada del sensor avanzado de campo amplio (AWiFS, por sus siglas en inglés); datos de elevación proporcionados por la misión topográfica de radar a bordo del transbordador espacial (SRTM, por sus siglas en inglés), y el índice de área foliar (LAI, por sus siglas en inglés) basado en el espectrorradiómetro de imágenes de resolución media (MODIS, por sus siglas en inglés). Para evaluar el desempeño de la simulación, las condiciones limítrofes del suelo, tanto controladas (por defecto) como modificadas, se comparan con datos in situ procedentes de una red automatizada de estaciones meteorológicas operada por la Agencia India de Investigación Espacial. En la corrida modificada, el modelo captó con mayor precisión la evolución temporal de temperatura superficial, humedad relativa, velocidad del viento, presión superficial y radiación solar. La mejora de estas variables meteorológicas cercanas a la superficie en pronósticos de 24 horas fue de 15 a 30\%. Pruebas ulteriores del desempeño del modelo para realizar pronósticos de ocho días de variables micrometeorológicas mostraron que la corrida modificada produjo resultados consistentes. Los valores promedio de la raíz del error cuadrático medio (RMSE, por sus siglas en inglés) para temperatura mínima y máxima, velocidad del viento, humedad relativa y precipitación son 2.5 y $3{ }^{\circ} \mathrm{C}, 2 \mathrm{~m} \mathrm{~s}^{-1}, 18 \%$ y $3.5 \mathrm{~mm}$, respectivamente. La modificación ayudó al desempeño del pronóstico mediante la disminución de la propagación de errores. Por lo tanto, se enfatiza el hecho de que una mejor representación de los parámetros de superficie tiene un efecto evidente en simulaciones del tiempo a escala local o regional. En países como la India, donde los mecanismos de retroalimentación tierra-atmósfera son más prominentes debido a características climáticas inherentes, es crucial mejorar los datos del estado inicial del suelo.
\end{abstract}

\begin{abstract}
Land surface processes play a critical role in governing the surface energy partitioning and the atmospheric circulation within a climate system. Improper representations of present land state, particularly spatially specific fields such as land cover, topographical and biophysical parameters contribute to the uncertainty in the model's weather simulations extending from local to regional scales. The present study investigates the impact of superior land surface datasets on the performance of the Weather Research and Forecasting
\end{abstract}


(WRF) model in simulating micrometeorological/near-surface weather, particularly sensible variables such as temperature, relative humidity, solar radiation and wind speed. The hypothesis is that the updated land surface datasets would help in improving micrometeorological forecasts over the domain comprising of Punjab, Haryana and Uttarakhand states in India. A land use land cover (LULC) dataset derived from Advanced Wide Field Sensor (AWiFS); an elevation dataset from the Shuttle Radar Topography Mission (SRTM), and a Leaf Area Index (LAI) based on the Moderate Resolution Imaging Spectroradiometer (MODIS), are used in model initialization. Performance evaluation of the model's simulation is done for controlled (default) and modified land boundary conditions with in situ weather from a network of automatic weather stations (AWS) operated by the Indian Space Research Organization (ISRO). In the modified run, the model more closely captured the temporal evolution of surface level temperature, relative humidity, wind speed, surface pressure and solar radiation. Improvement in 24 -hr forecast ranges from 15 to $30 \%$ for these near-surface weather variables. Further testing of the model's performance on its capability to forecast 8-day micrometeorological weather variables revealed that the modified run gave consistent results. The average RMSE values for minimum and maximum temperature, wind speed, relative humidity and precipitation are 2.5 and $3{ }^{\circ} \mathrm{C}, 2 \mathrm{~m} \mathrm{~s}^{-1}, 18 \%$ and $3.5 \mathrm{~mm}$, respectively. The modification helped in increasing the lead-time of the model's forecast by reducing the propagation error. Thus, this study emphasizes the fact that improved representation of land surface parameters has a definite effect on weather simulations at local to regional scales. For a country like India, where the feedback mechanisms between land and atmosphere are more prominent due to inherent climatic characteristics, it is critical to concentrate and improve on the inputs that represent the initial land state.

Keywords: Numerical weather prediction, WRF, land surface modeling, remote sensing data, near-surface weather forecasts, AWiFs, MODIS LAI, SRTM DEM.

\section{Introduction}

The availability of high-resolution weather forecasts at different time scales has gained importance in a wide range of applications for optimized decision-making. Particularly, agricultural and hydrological impact studies require micrometeorological/ near-surface weather forecasts at considerable quality on various spatial and temporal domains. Regional weather models use mathematically modeled relationships to downscale the global outputs from global circulation models (GCMs) available at coarser resolutions, with the help of local land state conditions. Based on the initial state of the atmospheric and land boundary conditions, the land fluxes evolve in three dimensions to reproduce the structure of the planetary boundary layer (PBL) at different vertical levels, which enables circulations between horizontal columns as a resultant of the simulated energy fluxes. From previous studies (Segal and Arritt, 1992; Yang et al., 1994; Ge et al., 2008; Sertel et al., 2009), it is apparent that differential heating due to heterogeneity in the underlying earth surface gives rise to atmospheric circulation in the PBL over a wide range of spatial and temporal scales. Increased latent heat flux humidifies the PBL and increases the moist static energy (MSE) of the near-surface air, consequently leading to the convergence of clouds
(Eltahir, 1998). The coarser resolution and outdated nature of the land-state input datasets often failed to capture the recent fine scale heterogeneities of the land concerning topography, soils, land cover and other land surface properties, which are very critical to the model's simulation at local and regional scales. Improper representation of land surface parameters derived from climatological datasets induced uncertainty in the model's simulation of weather (Prabha et al., 2011; Xue et al., 2014). In recent years, with the availability and easy access of satellite data, many studies have emphasized the role of high-resolution land surface boundary datasets in producing more precise weather forecasts with finer spatial resolution $(<15 \mathrm{~km})$ (Matsui et al., 2005; Ravindranath et al., 2010; Kumar et al., 2013). Walker et al. (1996) have demonstrated a strong dependence of mesoscale atmospheric model simulations on the local geographic data representation with detailed discussion on surface elevation and its representation within the model. They have explained that elevation plays a critical role in most of the mesoscale models not only due to its role in defining the nature of the lower boundary but also the landform representation derived from the Digital Elevation Model (DEM) from the Shuttle Radar Topography Mission (SRTM) modifies spatial/grid discretization. Among the significant land 
surface characteristics, leaf area index (LAI), topography, soil type and moisture, fractional vegetative cover, roughness length, and albedo play substantial roles in meteorological modeling (Crawford et al., 2001; Pienda et al., 2004). Kurkowski et al. (2003) observed improvement in surface temperature forecasts after using updated fractional vegetation cover dataset from the Advanced Very High-Resolution Radiometer (AVHRR) in the Eta model. He et al. (2017) updated all the land surface information fields like elevation, land-use data, vegetation fraction data and soil type data in the Weather Research and Forecasting (WRF) model and tested its capability of simulating near-surface temperature and precipitation. They concluded that the modified land surface representation had significant impacts on temperature and precipitation simulations reducing the root mean squared error values by 7 and $2.3 \%$, respectively. Sun et al. (2017) demonstrated the sensitivity of WRF model to the selection of land-use dataset and the land surface models in simulating sensible near-surface weather variables. The study showed significant improvements in the near-surface weather forecast for complex terrain.

This study incorporated the latest and updated high-resolution (56 m) land use/land cover (LULC) dataset in the WRF model. The DEM at a resolution of $90 \mathrm{~m}$ represented the topography of the domain in a spatially explicit manner within the model. A monthly varying LAI dataset derived from the Moderate Resolution Imaging Spectroradiometer (MODIS) is added as an additional input to the model. The study tried to capture the difference in the model's forecast capability with the existing sources of land surface information as against the updated datasets for a 24-h forecast period. It also focused on quantifying the impact of the proposed methodology (modified datasets) on eight-day forecasts of micrometeorological weather variables in the study domain. Key objectives of the study can be listed as: $(i)$ investigation of the changes in the representation of the datasets at model's resolution, (ii) quantification of the impact of updated land surface parameters on micrometeorological weather simulations at local (at selected stations) and regional (domain-averaged) scales, and (iii) evaluation of the impact of modification on the model's performance in forecasting micrometeorological weather variables for an extended time period (eight days).

\section{Data and methods}

\subsection{Study domain}

The study area covers Punjab, Haryana and Uttarakhand states, which are located in northern India. Punjab and Haryana are well-formed plains with elevation ranging from 200 to $800 \mathrm{~m}$. They comprise the intensive agricultural zones of the country with urban parcels in growing phase after the late 1990s. Uttarakhand is located in the foothills of the Himalayan mountain ranges, having $86 \%$ of mountainous area, $65 \%$ of its territory being covered with forest land-use. The regions of interest receive most of the rainfall from the south-west monsoon covering the months of June to September.

\subsection{Model description and setup}

The WRF model (Skamarock et al., 2008) version 3.4.1 (http://www.wrf-model.org) was used for forecasting weather parameters in this study. The mesoscale numerical model serves both for operational forecasting and regional atmospheric modelling. It is a limited-area, non-hydrostatic (with hydrostatic option) primitive equation model with multiple options for various physical parameterization schemes. Physics options used in this study include the Kain-Fritsch cumulus parameterization scheme (Kain, 2004) and the Purdue Lin scheme (Lin et al., 1983) for microphysics. The planetary boundary layer parameterizations are based on the Yonsei University boundary layer scheme (Hong et al., 2006), and definition of the land surface process is based on the multi-layer Noah land surface model (LSM) model (Chen and Dudhia, 2001). The long-wave radiation scheme is based on the Rapid Radiative Transfer Model (RRTM) (Mlawer et al., 1997) and the Dudhia scheme (Dudhia, 1989) represents short-wave radiation. The selected set of physics options has proven to give good results for the Indian domain (Ravindranath et al., 2010; Kumar et al., 2013).

The setup contains three domains configured with one parent and two nests implemented with two-way nesting options. The three domains were run at 15 , 5 and $1 \mathrm{~km}$ resolutions, respectively (Fig. 1). The centre point was fixed at $76^{\circ} 14^{\prime} 13^{\prime \prime} \mathrm{E}, 30^{\circ} 18^{\prime} 8^{\prime \prime} \mathrm{N}$ with the parent domain (15 km resolution) covering parts of Asia $(225 \times 270$ grid points $)$. The first nest ( $5 \mathrm{~km}$ resolution) has $325 \times 375$ grid points spanning 
to an extent covering northern parts of India. The second nest $(1 \mathrm{~km})$ roughly delimits the study area with $575 \times 550$ grid points and is the domain used for analysis. All the domains are terrain-following and have 36 vertical levels with the top of the atmosphere located at $50 \mathrm{hPa}$.

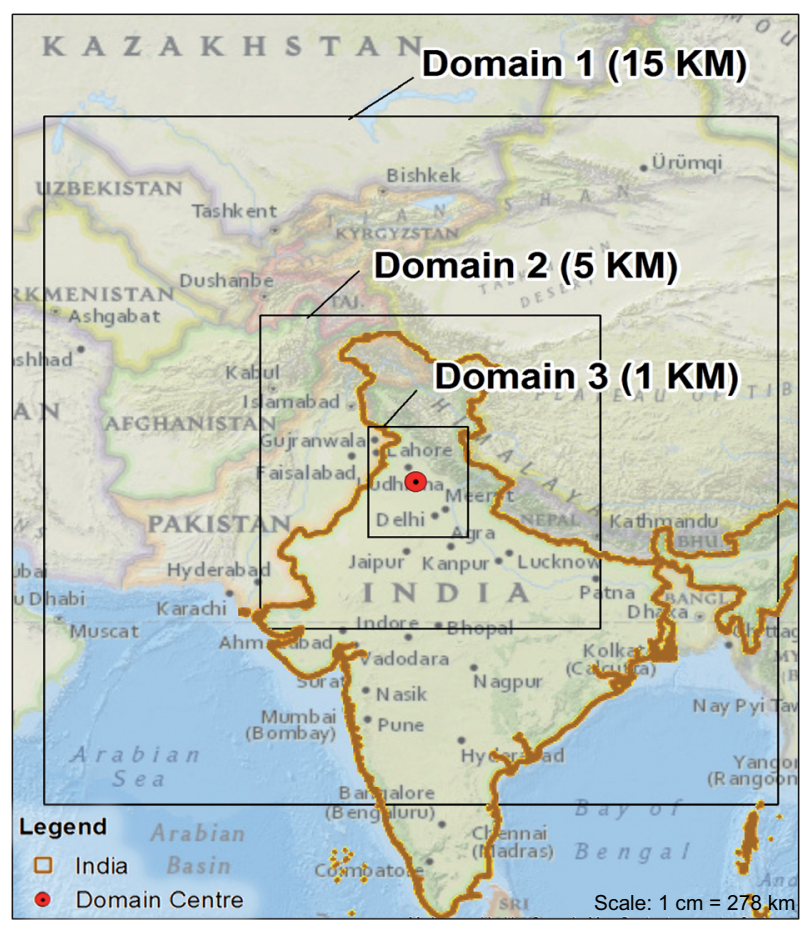

Fig. 1. Model domains.

\subsection{Simulation experiments}

The control run represents a simulation by the WRF model with the default datasets, and the modified run is the simulation with updated datasets.

\subsubsection{Case 1}

Two experiments with default conditions (control) and updated datasets (modified) were run for $24 \mathrm{~h}$ from 0000 GMT starting on October 1, 2008. The evaluation was done for the 12-h period from 1200 GMT allowing the first $12 \mathrm{~h}$ as model's spin-up time. Lin et al. (2016) concluded that the impacts on near-surface variables are high during nighttime for the non-urban areas and thus the simulation time was selected to comprehend the maximum variation. The month of October was chosen to demonstrate the ability of the model to simulate sensible weather variables on a calm/stable day with fewer disturbances.
October 1, 2008 had temperatures ranging from 23 to $27^{\circ} \mathrm{C}$, average wind speed of $0.5 \mathrm{~m} \mathrm{~s}^{-1}, 80 \%$ humidity and no rainfall.

\subsubsection{Case 2}

Two experiments with default conditions (control) and updated datasets (modified) were run for $48 \mathrm{~h}$ from 0300 GMT initialized on October 16, 2008. The evaluation was done for a $24-\mathrm{h}$ period from 0300 GMT allowing the first $24 \mathrm{~h}$ for spin-up of the model. October 17, 2008 had strong showers only at stations located in hilly regions (Shivalik hills and adjacent areas). Thus, this date was specially chosen to test the impact of alteration of land parameters on the model's performance in capturing short duration spells due to local disturbances (which is usually common in October).

\subsubsection{Case 3}

An experiment with updated datasets was run for eight days from March 24-31, 2009. The model was initiated at 0300 GMT on March 24 and evaluated from March 25, allowing for a $24 \mathrm{~h}$ spin-up time. The case study aims to analyze the ability of the updated model to forecast weather for longer lead times.

\subsection{Model input data and analysis}

\subsubsection{Land surface datasets}

The role of vegetation parameters in WRF is to estimate evapotranspiration components such as soil evaporation, wet canopy evaporation and canopy transpiration, and thus simulate surface energy balance in the Noah land surface model. Besides, land-use types also represent land surface parameters like albedo, roughness, emissivity and LAI within the model that are vital parameters, accounting for the energy partitioning at the surface. DEM is used in determining the displacement height and roughness length in the lower surface level, modulating the surface heat fluxes and the exchange coefficients within the planetary boundary layer (Chen and Dudhia, 2001).

Most of the studies using meteorological models (MM5, Eta, REMO, RCM) including the WRF had been using coarser resolution data. For example, LULC at $1 \mathrm{~km}$ resolution based on the U.S. Geological Survey (USGS) land classification scheme derived from 1-yr (1992-1993 cycle) temporal AVHRR 
data (Loveland et al., 2000). The USGS data lacks the finer details of land cover classes and presumably are outdated since significant changes in global land cover took place post-1993 (Ravindranath et al., 2010). In this study, multi-temporal satellite datasets from the Advanced Wide Field Sensor (AWiFS) onboard the IRS-P6 satellite, is used to derive LULC maps based on supervised classification (2008-2009 cycle), which is also verified by ground truth procedures (Biswadip, 2014). AWiFS has a spatial resolution of $58 \mathrm{~m}$, and the land-use was prepared at a scale of about 1:250 000 under national repository programs of the Indian Space Research Organization (ISRO). AWiFS LULC captures the spatial variability of the cropping pattern using three land-use classes, viz. Kharif, Rabi and Zaid, representing the different crop seasons in India. The product also accurately represents other land-uses like forest types, urban, water bodies and wasteland. As concluded by Sertel et al. (2009), the default land-use data is affected by outdated nature and misclassification of the land-use type due to the coarser resolution. In domains 2 and 3, which comprise the region of interest, both errors are prevalent. Land use changes are widespread in the Indo-Gangetic plains (Fig. 2a, b) aligned with the observations made by Ravindranath et al. (2010). For example, about $22 \%$ of the area that was classified as dry cropland in the USGS dataset has been categorized as irrigated cropland in the AWiFS dataset, which is the reflection of technological advancements post 2000 . The increase in barren lands due to land degradation in the neighborhood of the Thar Desert, Rajasthan, has led to extended desertification, which is captured well in the updated LULC dataset. Urban areas surrounding Delhi, as well as in Punjab and Haryana states have drastically increased since the 1990s (Rahman et al., 2011); accordingly, 7\% of irrigated cropland and $2 \%$ of shrubland category in the default data belongs to urban land-use in the modified dataset. Snow cover over the northern part of Jammu and Kashmir has increased marginally, while the barren lands have declined significantly. Misrepresentations are prominent in the forest regions where 5 and $3 \%$ of evergreen forest (actual land-use) appear

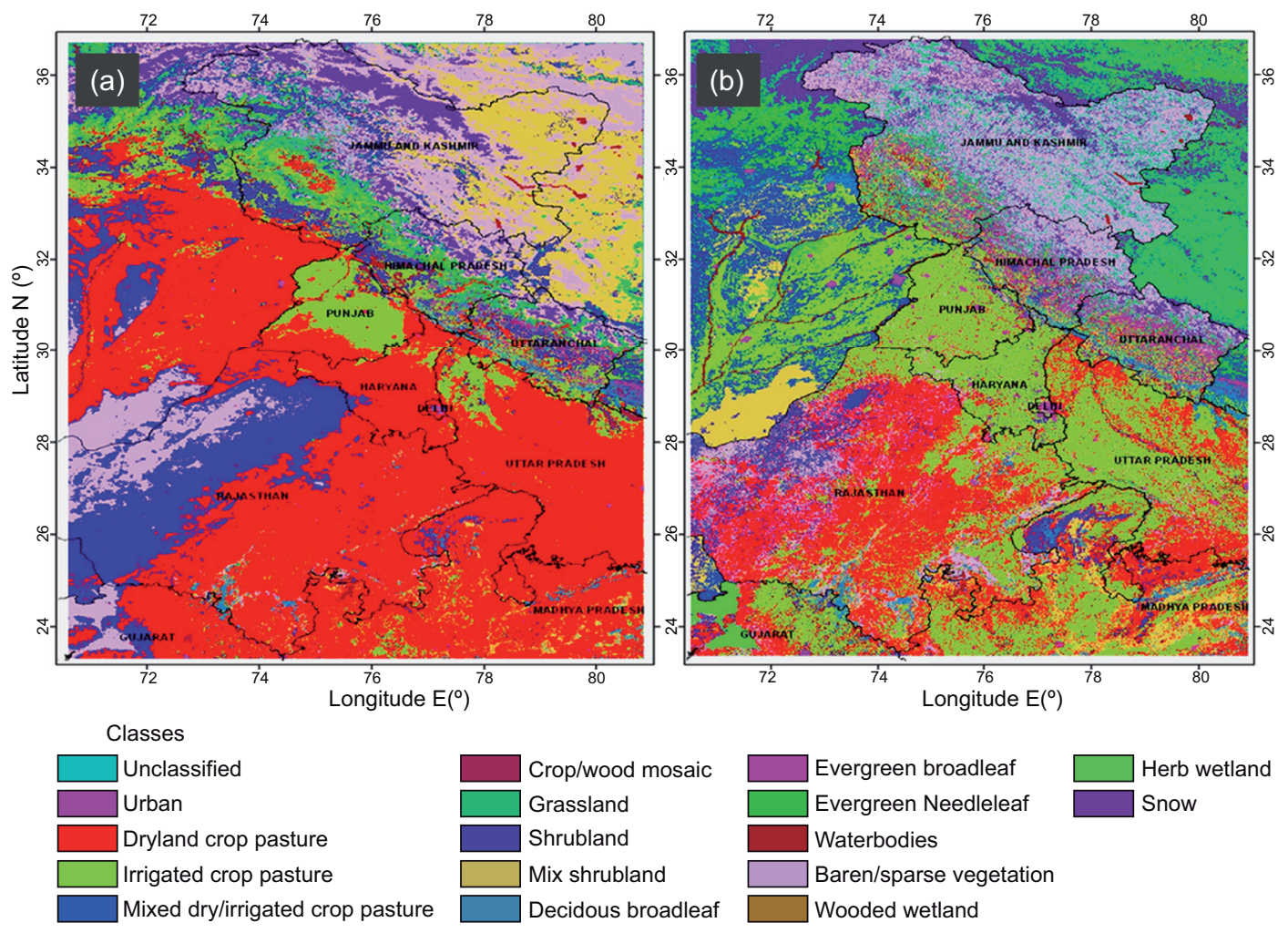

Fig. 2. Dominant land use/land cover categories. (a) Default (USGS) land cover data. (b) Modified (AWiFS) land cover data. 
as deciduous forest and shrubland categories in the default dataset. Similarly, about $2 \%$ of the deciduous forest was represented as cropland in the default dataset. Thus, an overall change of about $40 \%$ is observed within the study area, which makes the modified dataset very pertinent to the study. The modification captures the spatiotemporal variability of the dynamic land-use types in the region of interest. Figure 3 exemplifies a prominent case in the Uttarakhand region, where the better representation of the landuse variability in Shivalik and adjacent areas by the modified dataset is evident.

The terrain is represented with the latest $90 \mathrm{~m}$ resolution DEM from the SRTM, a joint NASA-NGA partnership, available from http:// srtm.csi.cgiar.org. The accuracy of the generated DEM is high, which is validated across the globe. The distinct differences are exhibited in areas with complex terrain, while in plains contrasts are marginal. For example, Figure 4 represents the variation in the elevation of Uttarakhand state captured well by the SRTM dataset. The default coarser resolution DEM showed a gradual increase in elevation, while the modified DEM captures the variability in elevation, particularly over the Shivalik ranges (lower Himalayan regions), the valley in between (Dehradun and adjacent areas), and the increasing elevation towards the upper Himalayas, which is not prominent in the former.

LAI is defined as a one-sided green leaf area per unit ground area. Conceptually it is a representation of the amount of ground covered or left uncovered. The model typically uses a default lookup table (LUT) approach in which a constant LAI is assigned to each USGS land-use category. Such static LAI for each land cover category at model's resolution often fails to capture the spatial and temporal heterogeneity of the index, which is the vertical component of the vegetation. LAI is essential to address the partitioning of energy between latent and sensible flux components. Prescription of spatially and temporally explicit information on LAI to the WRF model is thus inevitable (Tian et al., 2004). Model initialization is done with a freely available and globally validated MODIS-LAI product (Pandya et al., 2003; Yuan et al., 2011). The eight-day composite LAI product at 1-km resolution is obtained from https://lpdaac.usgs.gov, a website maintained by the NASA Land Processes Distributed Active Archive Center (LP-DAAC), which is processed to get monthly LAI datasets. (a)

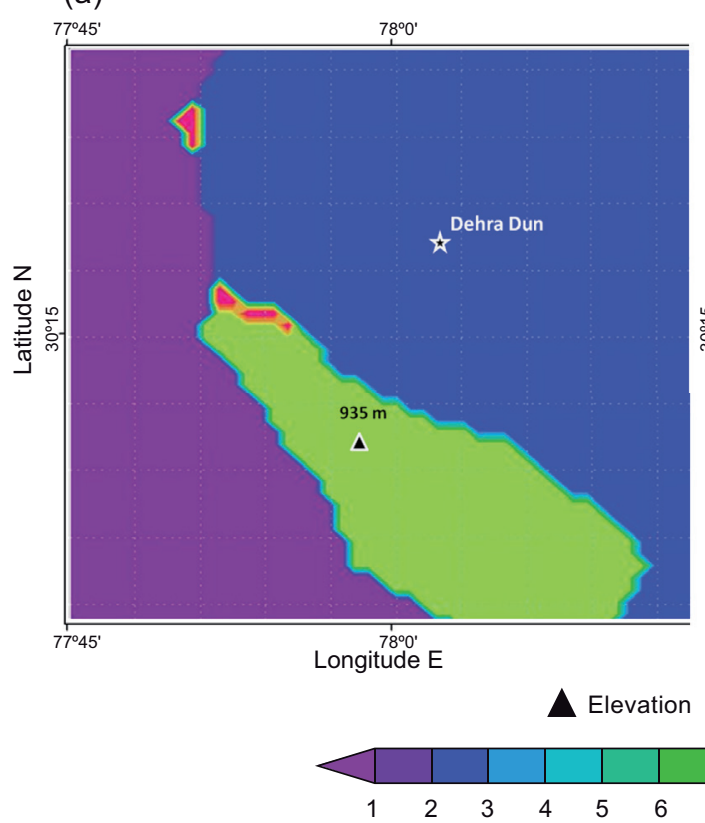

(b)

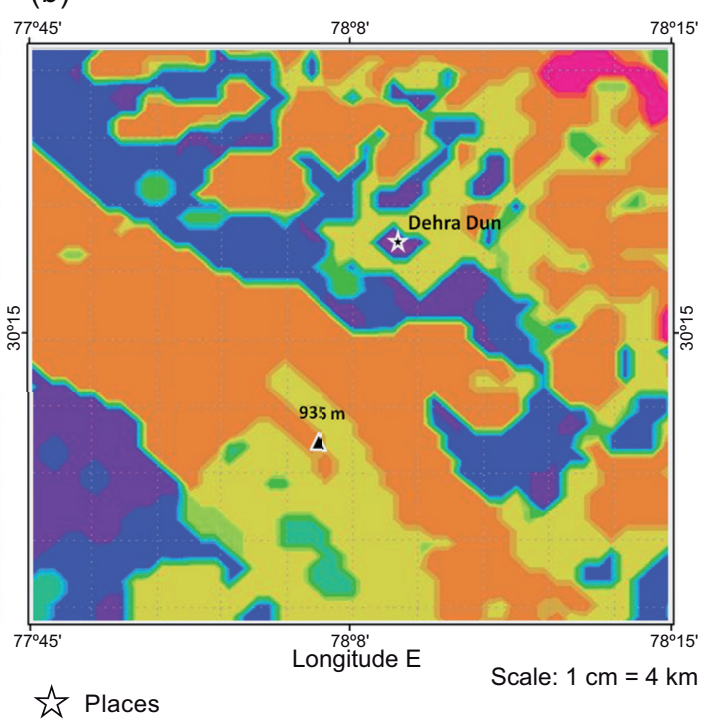

Fig. 3. Comparison between land use and land cover represented at model's resolution (1 km). (a)

Default (USGS). (b) AWiFS data modified input. 
(a)

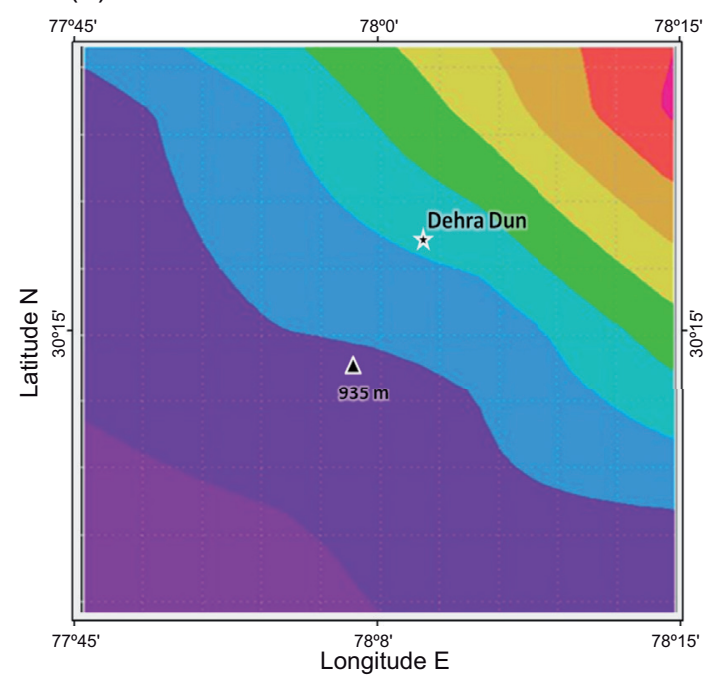

$\triangle$ Elevation

(b)
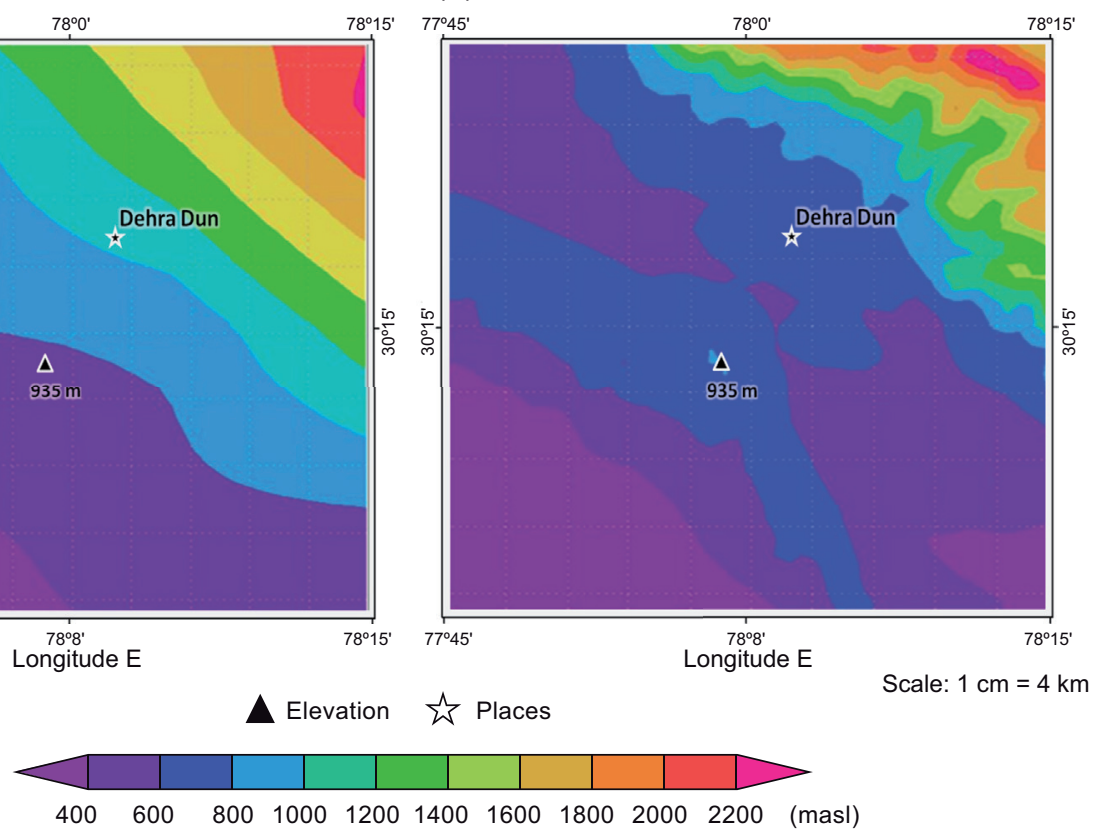

Fig. 4. Complexity of the terrain (m) captured at models' resolution (1 km). (a) Default (DEM [GTOPO 30]). (b) DEM (SRTM) modified input. The units are in meters above mean sea level.

Significant dissimilarities are observed throughout the study domain, revealing that the new LAI information from MODIS has better captured the spatial and temporal variability of LAI within individual vegetation land-use types. On the contrary, LAI based on the LUT approach yielded unrealistic values. For instance, LAI values are in the range of 4-5 for the deciduous forest in Shivalik hills, which is a rarity at the beginning of the winter season due to shedding of leaves. In another instance, modified dataset correctly captured low LAI values occurring in the agricultural lands of Punjab due to maturity/harvest of crops during October, while the default LUT approach showed LAI values in the range of 3.5-4, which is considerably high in that month (Fig. 5).

The different land surface datasets used for the simulations are tabulated in Table I. Upscaling from finer resolution to coarser resolution is always superior to direct usage of the coarser dataset, which is addressed in this study. Even if the model is implemented in coarser resolutions, an external upscaling of the modified input like the one explained below is necessary to avoid interpolation uncertainties being introduced within the model. Smoothening of the finer resolution images (to avoid noise) are performed externally, and the smoothened dataset is upscaled to the model's resolution (here, $1 \mathrm{~km}$ ) using the nearest neighbor method, before feeding input into the model. Walker and Leone (1994) demonstrated the importance of smoothening, especially for DEM. Figures 3-5 represent the high variability at model's resolution, thus proving the need for external smoothening and interpolation to retain essential classes/values.

\subsubsection{Initial and boundary data}

The initial and lateral boundary conditions for the WRF model are provided by the Global Forecast System (GFS) data, downloaded at a $0.5^{\circ}$ resolution with 47 pressure levels. GFS is a coupled spectral model that provides global forecasts from one to 16 days. Data is downloaded at 1200 GMT model cycle with three-hourly forecast intervals to match with the model simulation dates mentioned in section 2.3.

\subsection{Evaluation methods}

The performance of the WRF model for different cases is evaluated with the data of 15 automatic weather stations (AWS) installed by the Indian Space Research Organization (ISRO) within Punjab and Haryana 
(a)

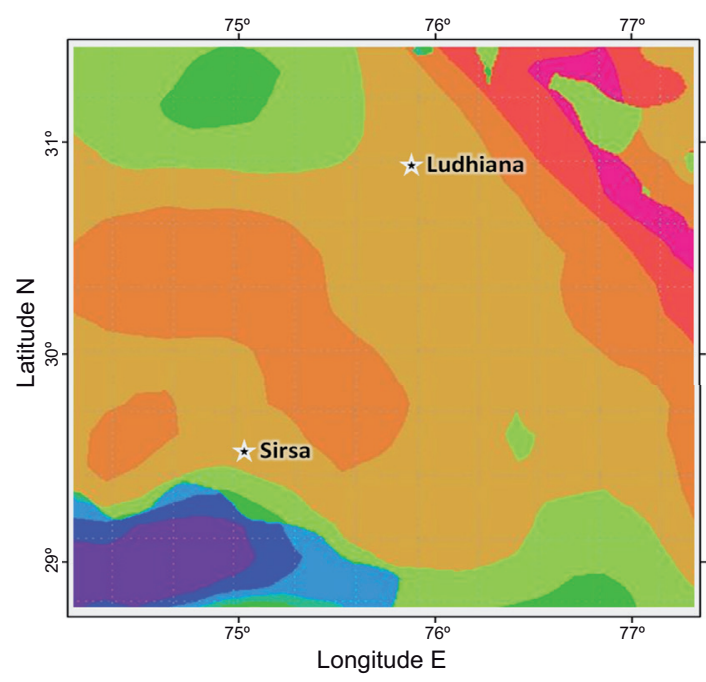

(b)

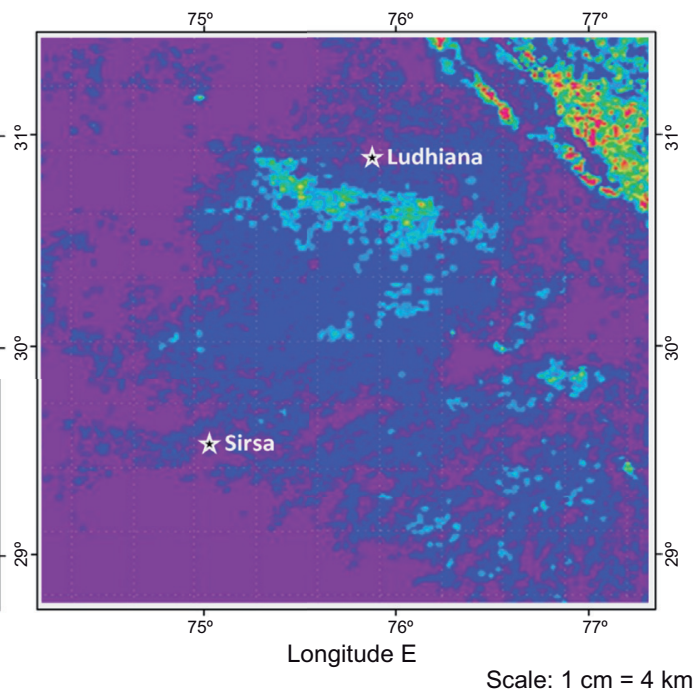

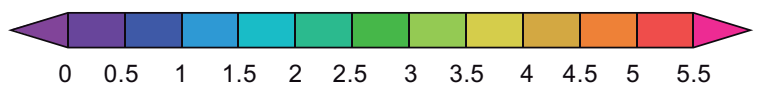

Fig. 5. Representation of LAI $\left(\mathrm{m}^{2} \mathrm{~m}^{-2}\right)$ between the two sources at model's resolution $(1 \mathrm{~km})$. (a) Default ( LUT-USGS land use classes). (b) MODIS LAI (modified input).

Table I. Land surface inputs for the control and modified runs of the WRF.

\begin{tabular}{clll}
\hline Station number & Land surface parameter & Control run & Modified run \\
\hline 1 & LULC & USGS-LULC $(1 \mathrm{~km})$ & AWIFS-LULC $(56 \mathrm{~m})$ \\
2 & LAI & Default LUT approach & MODIS-LAI $(1 \mathrm{~km})$ \\
3 & Elevation & GTOPO $(1 \mathrm{~km})$ DEM & SRTM $(90 \mathrm{~m})$ DEM \\
\hline
\end{tabular}

(Fig. 6a). The bilinear interpolation method is used to select the pixel from the model's output that is closest to the observational station. Temperature and humidity are considered at a $2 \mathrm{~m}$ height while wind speed is considered at a $10 \mathrm{~m}$ height for verification.

Statistical measures such as mean bias, root mean square error (RMSE) and mean absolute percent error (MAPE) are used to evaluate the performance of the WRF model's forecast. RMSE serves to aggregate the magnitudes of errors in predictions for various times into a single measure of predictive power, and is a good measure to compare forecasting errors of different models for a particular variable. MAPE essentially combines the individual percentage errors without offsetting the negative and positive values.

The improvement factor, which is found to be very relevant to compare the performance of climate models/simulations (Kumar et al., 2013), is used to compare the performance of the control and modified runs. It provides the percentage improvement of one simulation (here, modified run) over the other (default run), and is given by:

Improvement $=$ factor

$$
\frac{\left(\sqrt{\frac{1}{N} \sum_{i=1}^{N}\left(f_{i}^{c}-O_{i}\right)^{2}}-\sqrt{\frac{1}{N} \sum_{i=1}^{N}\left(f_{i}^{m}-O_{i}\right)^{2}}\right)}{\sqrt{\frac{1}{N} \sum_{i=1}^{N}\left(f_{i}^{c}-O_{i}\right)^{2}}} \times 100
$$

where $f_{i}^{c}$ is the forecast of the control run (WRFCNT) at the $i$ th observation, $f_{i}^{m}$ is the forecast of the modified run (WRF-EXT) at the $i$ th observation, and $O_{i}$ is the actual observed data at the $i$ th observation.

Individual sensitivity analyses for each parameter, viz. LULC, DEM and LAI, were performed. Only 

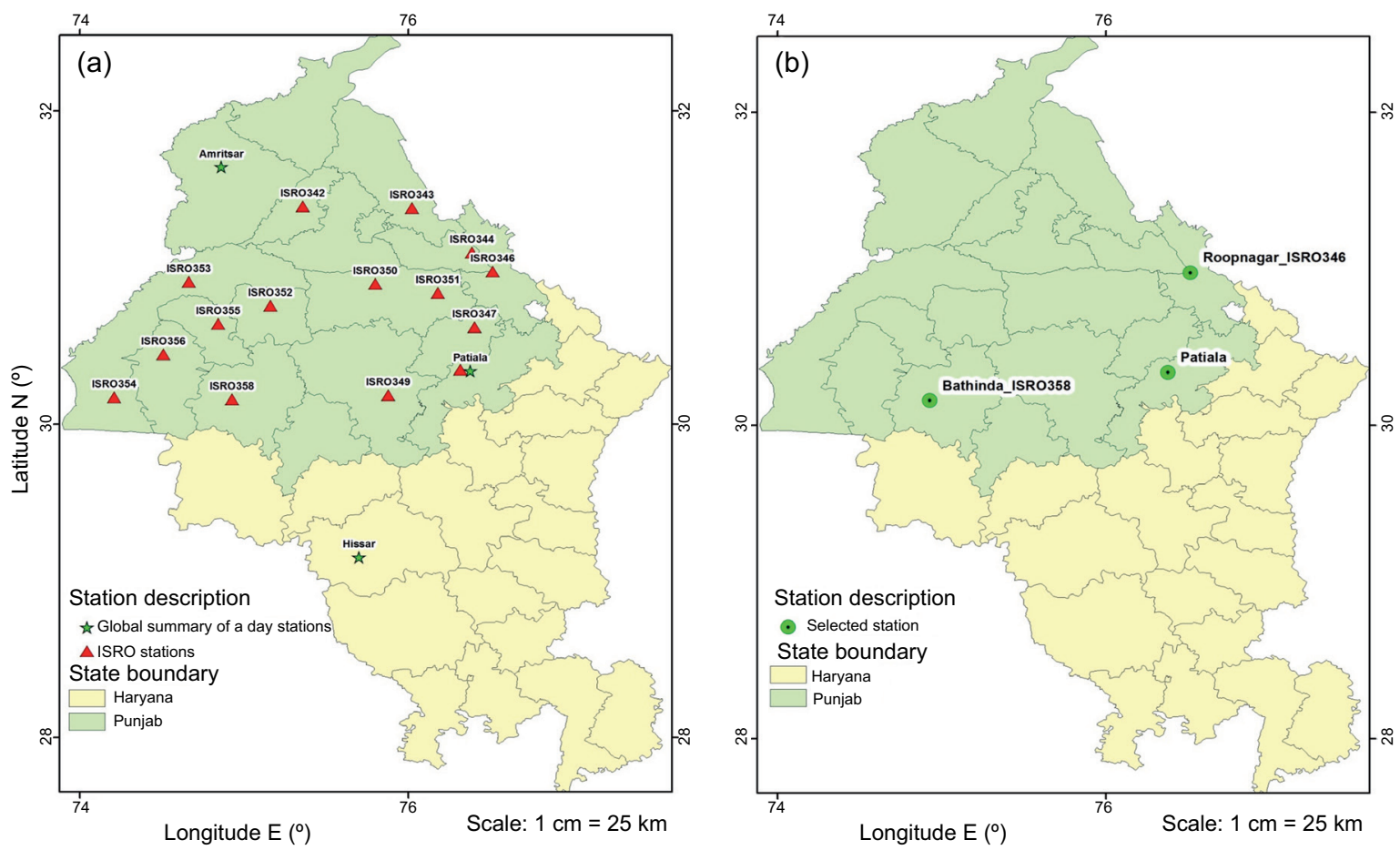

Fig. 6 Meteorological stations network. (a) Stations within the area of interest. (b) Selected meteorological stations for validation.

marginal improvements are observed in those sensitivity experiments except for LULC, where a notable improvement in the simulated weather variables was observed. Since the land parameters selected for modification are complementary, combined sensitivity analysis yielded better results, and henceforth it is discussed in this manuscript.

\section{Results and discussion}

3.1 Effect of land surface boundary changes on weather forecast over a spatial domain

WRF simulations were spatially analyzed to characterize the behavior of positive or negative deviations in the forecasted parameters during a 12-h forecast period (Fig. 7). Pixel values are averaged across the time of simulation, and the difference between the modified and control run represents the mean bias image, which is used for investigating different weather variables.

The mean bias image (i.e., modified minus control) for temperature, ranged from -4 to $6{ }^{\circ} \mathrm{C}$ with major values ranging from -2 to $+1{ }^{\circ} \mathrm{C}$. The spatial temperature variation is a direct function of elevation and vegetation. The updated DEM and land boundary conditions adequately captured the process of differential heating over the surface and led to the alteration of energy fluxes contributing to the positive and negative bias in hilly regions and plains, respectively. On a spatial scale, the negative bias is predominant in the study domain, which shows that the modified run generated lesser night-time temperatures compared to the control run, reducing the well-known overestimation (night-time temperatures) issues in WRF (Zhang et al., 2013). For example, the plains of Haryana, where $25 \%$ of the land cover changed to irrigated cropland in the updated land cover dataset, a temperature bias of about $-2{ }^{\circ} \mathrm{C}$ for the late evening hours and $+1{ }^{\circ} \mathrm{C}$ for early morning hours is recorded. The observed bias in temperature is attributed to changes in the thermal inertia, surface roughness, albedo and stomatal resistance associated with irrigated cropland (Pienda et al., 2004). The major contributor is the low thermal inertia of irrigated cropland, since it could simulate a cooler layer in the evening and a warmer layer during the early morning. Figure 7a shows another instance where the temperature bias is very high in Shivalik hills and adjacent areas (Dehradun). The negative 
a)

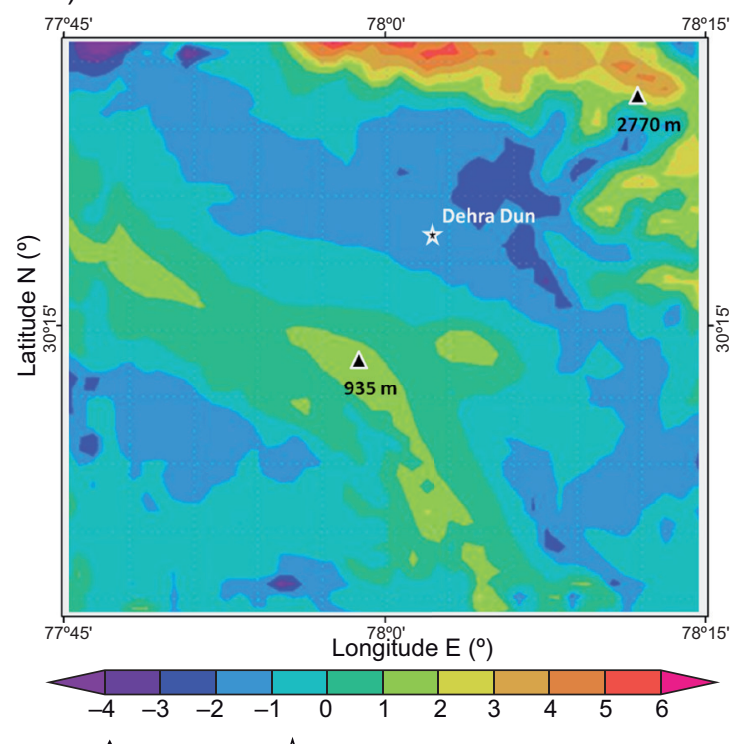

c)

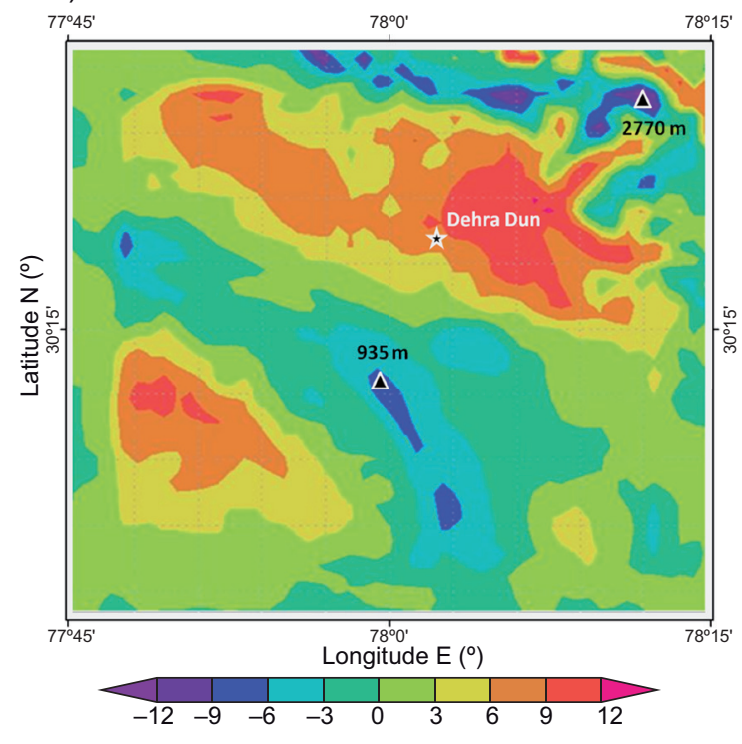

$\Delta$ Elevation ir Places Scale: $1 \mathrm{~cm}=4 \mathrm{~km}$ b)

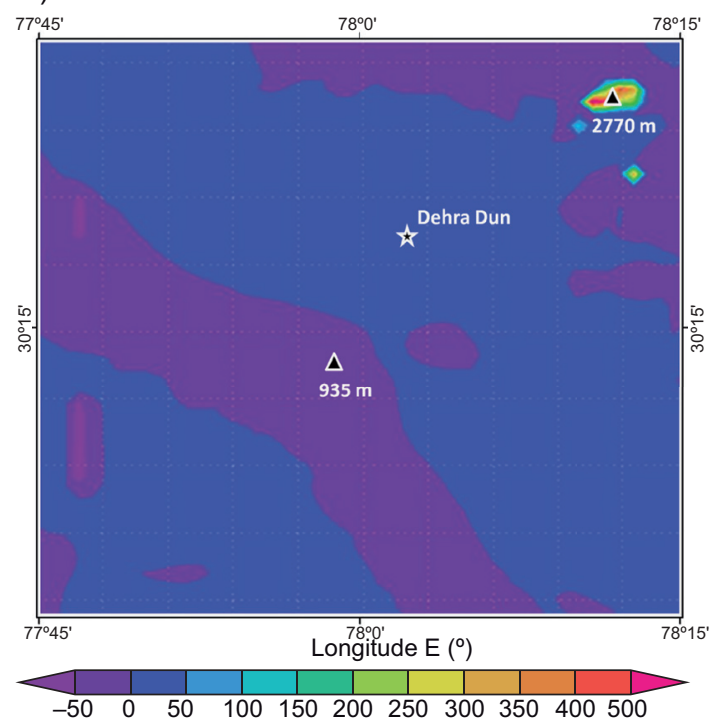

d)

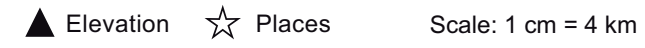

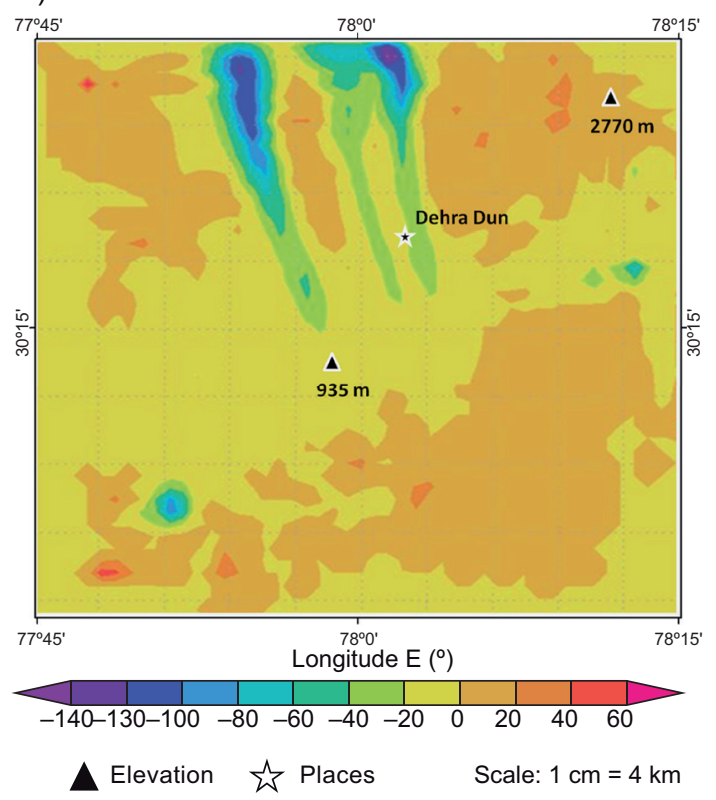

Fig. 7. Mean bias images showing the difference between modified and control run simulations. (a) Temperature bias image (in ${ }^{\circ} \mathrm{C}$ ) at $2 \mathrm{~m}$. (b) Solar radiation bias image (in $\mathrm{W} \mathrm{m}^{-2}$ ). (c) $\mathrm{RH}$ bias image $(\%)$. (d) Rainfall bias image $\left(\mathrm{mm}_{\text {day }^{-1}}\right)$.

bias (about $-3{ }^{\circ} \mathrm{C}$ ) is observed in valleys, where croplands are the predominant vegetation, and the positive bias (as high as $4{ }^{\circ} \mathrm{C}$ ) is noticed in the hilly terrain with forest cover. Forests serve as a heat-trap due to higher surface roughness and canopy cover, thus having higher nighttime temperatures than croplands (Lee et al., 2011). This phenomenon is captured well by the modified run, where simulated temperatures are high (low) in forest (croplands) regions.

The difference of relative humidity $(\mathrm{RH})$ at the 2-m level exhibited almost a similar pattern of spatial variation as temperature but an opposite behavior due to the inverse relationship between temperature and RH. The updated land surface boundary with distinct 
land cover changes in the valley and hilly areas of Uttarakhand (Fig. 7c) showed a significant difference in $\mathrm{RH}$ between the modified and control runs ranging from -12 to $12 \%$, with most values falling within -6 to $9 \%$. Earlier studies have reported underestimation (overestimation) of nighttime $\mathrm{RH}$ for croplands (forests). In agreement with the previous results, the negative bias is seen in the hilly forest regions and a positive bias is observed in the plains and valley areas with croplands, elucidating the improvement offered by the modified run.

The difference in solar radiation values ranged from -50 to $200 \mathrm{Wm}^{-2}$. Since during nighttime incoming solar radiation is not present, values are more representative of the emittance (long-wave radiation). The modified run gave slightly higher values (positive bias) in the plains and valleys, where the modified datasets improved the representation of emissivity.

Case 2 was used for evaluation of rainfall simulations. The bias in rainfall lies between -140 to 20 $\mathrm{mm}$ day $^{-1}$ for modified and control runs on a rainy day (from local disturbances). A positive bias of 2 to $5 \mathrm{~mm} \mathrm{day}^{-1}$ in rain precipitation was found across the plains, particularly in areas where agricultural land use has shifted from dry land to irrigated crop/ pasture. The substantial negative bias in some regions showed that the modified run reduced the false alarm simulated by the control run. A value of $140 \mathrm{~mm} \mathrm{day}^{-1}$ as forecasted by the control run is very unrealistic for October in the study domain and the modified run eliminated this error. The improved roughness and moisture flux simulations in the lower boundary layer helped to reduce the unrealistic rainfall alarm in the valley (Fig. 7d). The hilly areas covered with evergreen forests showed a realistic rainfall pattern in the modified run with an increased rainfall amount due to the improved representation of orography and LAI. The increased moisture availability at lower levels would have given the potential for convergence. Although the rainfall simulation from modified runs followed a similar pattern as that of observed values by reducing false alarms, the rainfall amount is largely overpredicted for this event. Rainfall is a result of combined processes of physics and dynamics at a certain location, and land surface changes alone are insufficient to capture the entire variability (He et al., 2017).

\subsection{Impact of land state changes on weather fore-} cast over selected stations

In order to evaluate the performance of the WRF model in a detailed manner, AWS at Roopanagar, Patiala and Bhatinda were considered (Fig. 6b). The selected stations represent the variability in topography and land-use of the study region. Roopnagar station exemplifies the hilly region and partly has forest cover; Patiala station is located in the transition region from the plains to the hilly zone, being mostly an agricultural area, and Bhatinda station is located entirely in the plains, belonging principally to the urban category. A grid of $10 \times 10 \mathrm{~km}$ assessed the percentage changes of land cover in the selected stations (Table II). The influence of the land state change is evaluated based on the degree of positive/negative mean bias and associated RMSE for the forecasted weather variables from the two experiments against the actual station data at these three locations (Fig. 8). It is evident that land surface changes have a more clear and profound effect on 2-m height air temperature simulations. For Patiala station, the land use in the model's default dataset is irrigated cropland $(80 \%)$ and urban (13\%), while AWiFS based land use consists of $68 \%$ irrigated cropland and $26 \%$ urban. Since there is not a profound change, temperature curves for the control and modified runs are relatively close (Fig. 8a). The relatively cooler simulated temperature during night hours in the modified run is possibly due to increased thermal inertia associated with the reduced irrigated crop areas and urban expansion. The model reproduced temperature reasonably well at the Patiala station but with a cold bias of $1.30^{\circ} \mathrm{C}$ in the modified run. A slightly high RMSE $\left(1.32^{\circ} \mathrm{C}\right)$ with new land surface boundary reveals that no improvements have occurred in the temperature simulation at Patiala station for the simulated time period. At Roopanagar, deciduous forest (40\%), which is the dominant land cover category, was misclassified as mixed dry/irrigated cropland $(54 \%)$ in the default dataset. Thus, as a reflection, the model-simulated temperature remains high for the modified run when compared to the control run (Fig. 8b). As discussed in the previous section, the forest acts as a trap of energy and is comparatively warmer during nighttime, which is well captured in the modified run. The higher values of thermal inertia and less moisture availability due to reduced 
LAI, associated with the deciduous forest have led to reduced evaporative cooling and hence simulation of higher temperatures.

The modified run thus attempted to minimize the cold bias, and the new land boundary led to a reduction in RMSE from $2.28^{\circ} \mathrm{C}$ in the control run to $1.34{ }^{\circ} \mathrm{C}$ at this station. Our results are in line with those reported in previous studies (Pienda et al., 2004; $\mathrm{He}$ et al., 2017). Significant changes in land cover are observed at Bhatinda due to urbanization. Mixed dry and irrigated cropland categories in the default dataset have changed to urban land use in approximately $41 \%$. The model predicted cooler temperatures than the control run nearly for all forecast hours (Fig. 8c), which is attributed to the lowering of nocturnal warm bias. Cooler near-surface air temperature is simulated with the new land cover because of the modulation of the surface energy fluxes through changes in the parameters (albedo, surface resistance, roughness factor, and thermal inertia). Conversion of agricultural to urban land caused an increase in surface roughness length and thermal inertia, which in turn partitioned more energy to sensible and latent heat fluxes, which subsequently cooling down the layer near the surface (Nicholas and Lewis, 1980). Thus, the positive (warm) bias of temperature reduced from 1.9 to $0.9{ }^{\circ} \mathrm{C}$ at Bhatinda by modifying the land boundary (Table II). The modified run has also decreased RMSE $\left(1.08^{\circ} \mathrm{C}\right)$ compared to the control run at this site.

The modification of land boundary conditions did not show much difference in the simulated $\mathrm{RH}$ at $\mathrm{Pa}-$ tiala, which is identical with temperature simulations. The model predicted $\mathrm{RH}$ agreed with observation in the control run (bias $=-0.21^{\circ} \mathrm{C}$ ), but a positive bias $\left(3.26^{\circ} \mathrm{C}\right.$ ) is noticed in the modified run at Patiala (Table II). For the other two stations, the model mostly underestimated RH in both experiments, with a reduced magnitude of underestimation in the modified run. The updated model improves the prediction of $\mathrm{RH}$ at both stations, which is evident from the reduction in mean bias from -10 to $-7.65 \%$ at Roopanagar and -17.6 to $-11.2 \%$ at Bhatinda. Flaounas et al. (2010) reported similar results for RH simulations. The relatively higher humidity simulated with the new land cover could be attributed to the higher magnitude of fluxes, and more partitioning of energy to latent heat flux and sensible heat flux due to the conversion of irrigated cropland to deciduous forest or urban land cover. 

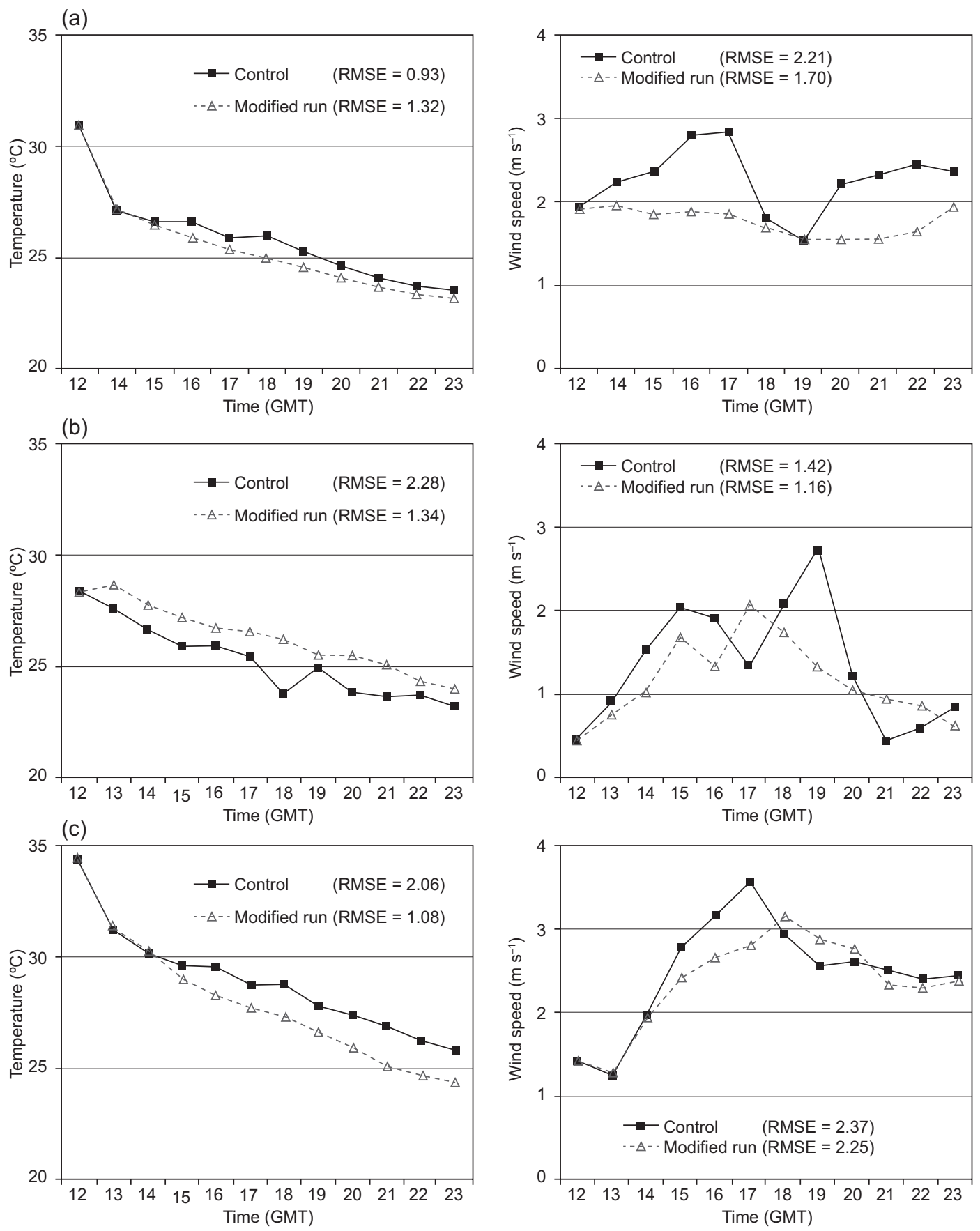

Fig. 8. Simulation of 2-m temperature and wind speed for 12-h forecast period over the three stations: (a) Patiala, (b) Ropnagar, and (c) Bhatinda.

Both control and modified runs produced a strong positive bias in wind speed during all the forecast hours (Table II). The simulated wind speed for both runs followed the observed wind speed patterns but largely over predicted the values (Fig. 8). Zhang et al. (2013) also observed the nighttime overestimation of wind values. We also noticed the overprediction of surface wind speed over plains and valley areas in the southwest of the study area and the underprediction over hilly regions in its northeast portion. 
Previous studies (Beljaars et al., 2004; Case et al., 2008; Jiménez and Dudhia, 2012) have reported similar results demonstrating the tendency of the WRF model to overestimate surface winds in the plains and underestimate its values over hilly terrain. A positive bias ranging from 1.04 to $2.41 \mathrm{~m} \mathrm{~s}^{-1}$ is noticed for all the three stations. The drag resulting from unresolved orography due to the lack of parameterization of fine roughness elements within the model is one of the primary reasons for the systematic positive bias in the model simulated wind speed (Jiménez and Dudhia, 2012). Also, the improper representation of the decoupling between near-surface and above-layer air by the model leads to the over-prediction of wind speed values, especially during the nighttime (Zhang
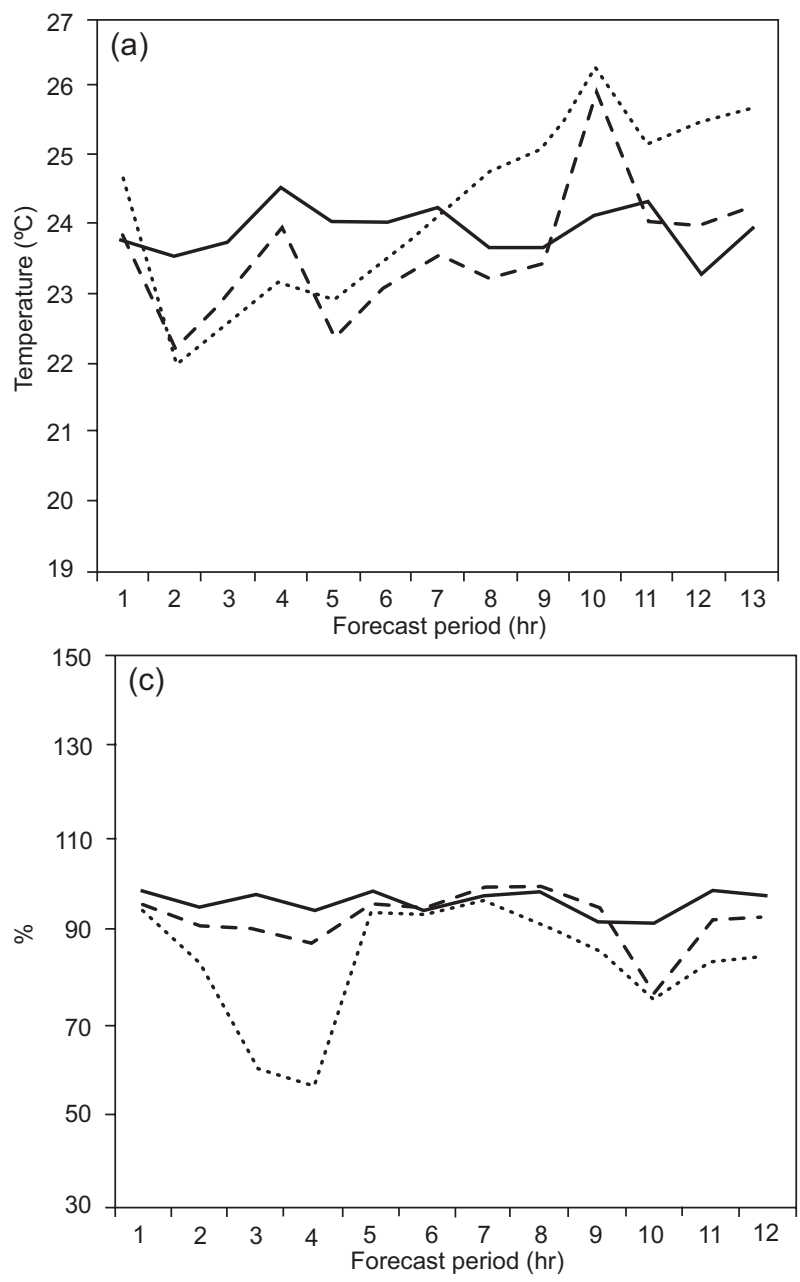

et al., 2013). The wind simulation agrees with the reports in peninsular India using the MM5 model (Srinivas et al., 2011). Marginal improvement in the simulated wind speed is noticed in the modified run. The updated land state parameters have led to predictable atmospheric circulation associated with realistic heating/cooling processes over these regions.

\subsection{Statistical analysis across available stations}

The temporal evolution of model-simulated mean weather parameters during forecast hours (beginning at 12:00 GMT) is compared to the corresponding temporal pattern of observations from a network of ISRO-AWS stations (Fig. 9). The correspondence and accuracy of the model simulations are evaluated with
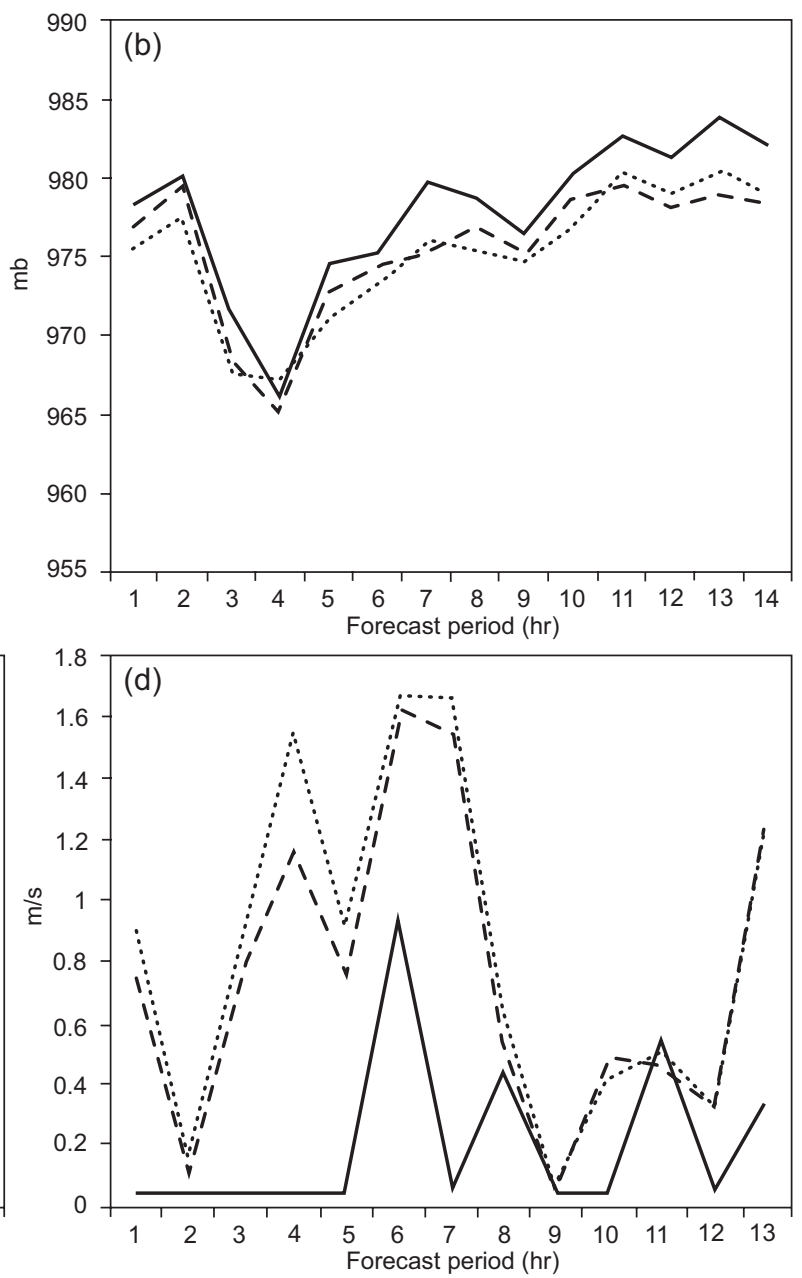

Actual station data

Default run - - Modifed run

Fig. 9. Comparison between simulations and actual station data across stations for a 12-h simulation, from 12:00 to 23:00 GMT on October 1, 2008. (a) Mean temperature. (b) Pressure. (c) RH. (d) Wind speed. 
Table III. Evaluation of WRF forecasts against ISRO-AWS station data.

\begin{tabular}{lcccccc}
\hline Variables & \multicolumn{2}{c}{ Control run } & & \multicolumn{2}{c}{ Modified run } & \multicolumn{2}{c}{$\begin{array}{c}\text { Improvement } \\
\text { factor (\%) }\end{array}$} \\
\cline { 2 - 3 } & RMSE & MAPE & & RMSE & MAPE & \\
\hline Temperature at $2 \mathrm{~m}\left({ }^{\circ} \mathrm{C}\right)$ & 1.75 & 5.61 & & 1.36 & 4.24 & 21 \\
RH at $2 \mathrm{~m}(\%)$ & 15.5 & 14.86 & & 10.8 & 10.1 & 30 \\
Surface pressure $(\mathrm{mb})$ & 5.19 & 0.36 & & 5.04 & 0.35 & 4 \\
Wind speed at $10 \mathrm{~m}\left(\mathrm{~ms}^{-1}\right)$ & 1.89 & 27.98 & & 1.65 & 23.9 & 13 \\
\hline
\end{tabular}

RMSE, MAPE and the improvement factor (Table III). The model has simulated cooler temperatures until midnight (i.e., 20:00 GMT) after which the values exceeded the observed values. The improvement factor of the modified run over the control run for surface temperature is $21 \%$ with a mean RMSE and MAPE of 1.36 and $4.24^{\circ} \mathrm{C}$, respectively. Results are in agreement with a similar study conducted in the Indian region by Srinivas et al. (2011). Among all variables under evaluation, $\mathrm{RH}$ showed the highest level of improvement during 12-h forecasts. The hourly pattern of simulated $\mathrm{RH}$ from the modified case closely followed the pattern of actual values. The improvement factor in $\mathrm{RH}$ with the altered land boundary conditions is $30 \%$. The modified run yielded a comparatively lower RMSE (10.8\%) and MAPE (10.1\%) than the control run. The model underpredicted the surface pressure, but it captured the hourly trend of observed surface pressure. The values of RMSE and MAPE for surface pressure did not show much difference between the control and modified experiments. The surface winds from the model are overestimated in both simulations. The RMSE and MAPE associated to the modified run are $1.65 \mathrm{~m} \mathrm{~s}^{-1}$ and $23.9 \%$, respectively. An improvement factor of $13 \%$ is noticed over the control run. The results confirm that there is a specific impact on temperature and RH simulations. The feedback mechanisms are captured accurately with the near-to-real representation of the land state parameters, which has led to the increase in the quality of forecasts made by the modified run (Tian et al., 2004).

\subsection{Evaluation of the temporal variability of near- surface variables}

The updated datasets are used in the WRF model to simulate micrometeorological weather for a longer time-period of seven days (with one-day spin-up time) (case 3). The results are tabulated in Table IV, which explains the temporal evolution of RMSE for various near-surface weather variables. Appreciable results are obtained for temperature simulations especially for maximum temperatures, which are simulated close to observations (Fig. 10a). A comparatively significant error in the simulated minimum temperature shows that the model has issues in reproducing nighttime temperatures as observed in section 3.1. Minimum temperatures for starting days (March 25-27, 2009) are underpredicted, while the remaining days are overpredicted

Table IV. Day-wise RMSE values for a seven-day forecast across stations.

\begin{tabular}{cccccc}
\hline Day & $\begin{array}{c}\text { Minimum temperature } \\
\text { at } 2 \mathrm{~m}\left({ }^{\circ} \mathrm{C}\right)\end{array}$ & $\begin{array}{c}\text { Maximum temperature } \\
\text { at } 2 \mathrm{~m}\left({ }^{\circ} \mathrm{C}\right)\end{array}$ & $\begin{array}{c}\text { Wind speed } \\
\left.\text { at } 10 \mathrm{~m}^{-1}\right)\end{array}$ & $\begin{array}{c}\text { RH at } 2 \mathrm{~m} \\
(\%)\end{array}$ & $\begin{array}{c}\text { Total precipitation } \\
(\mathrm{mm})\end{array}$ \\
\hline 1 & 3.17 & 3.87 & 2.24 & 7.51 & 3.84 \\
2 & 2.79 & 1.27 & 1.84 & 9.32 & 2.96 \\
3 & 2.17 & 3.46 & 1.63 & 19.88 & 13.77 \\
4 & 1.83 & 2.78 & 3.21 & 25.04 & 0.80 \\
5 & 1.92 & 3.21 & 2.72 & 28.44 & 3.11 \\
6 & 3.22 & 1.97 & 1.12 & 22.57 & 0.00 \\
7 & 2.82 & 1.49 & 2.14 & 15.98 & 0.00 \\
\hline
\end{tabular}



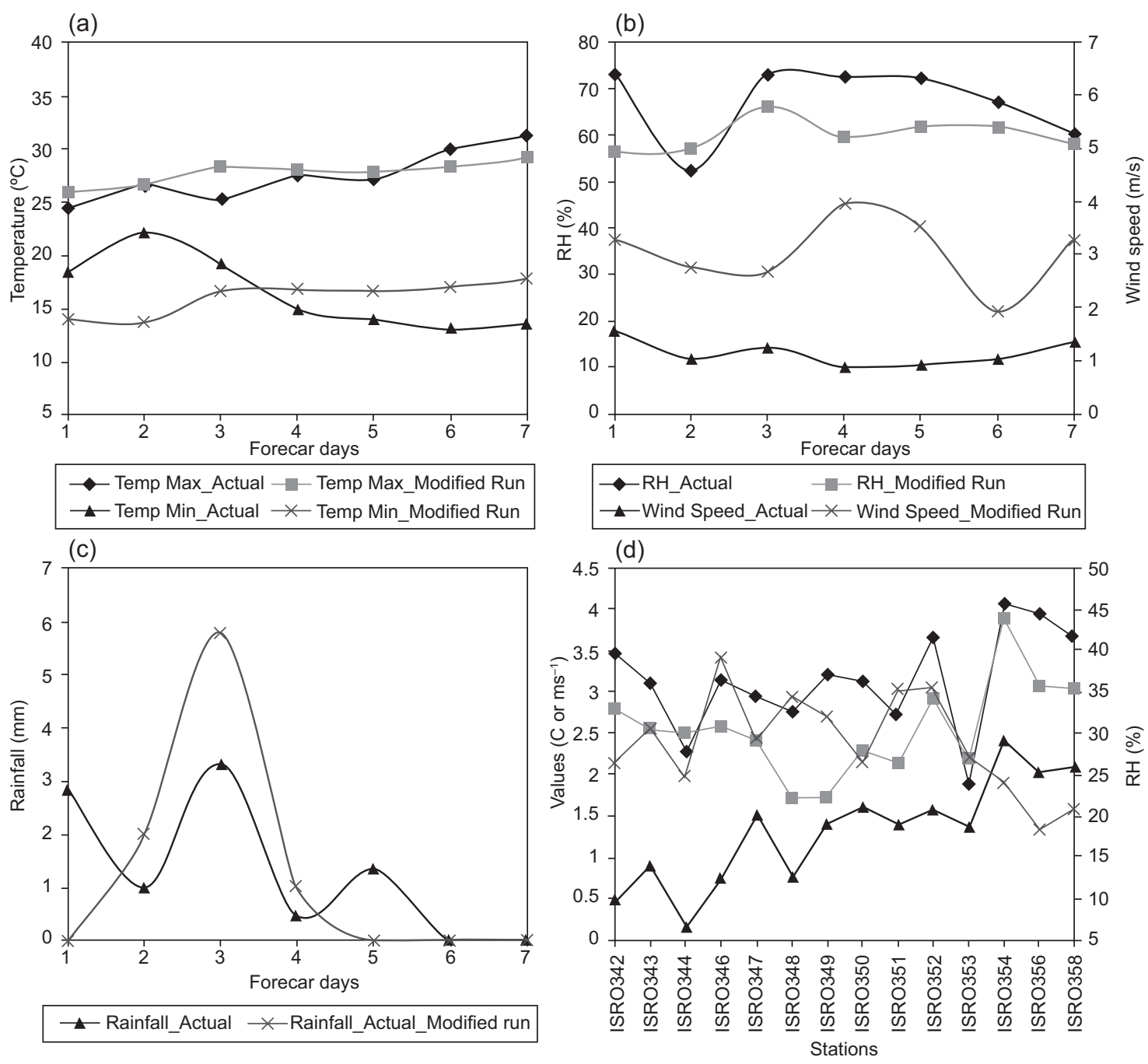

$$
\begin{aligned}
& \multimap \text { Temp min (C) }- \text { Temp Max (C) } \\
& \rightarrow \text { Wind speed }(\mathrm{m} / \mathrm{s}) \rightarrow \mathrm{RH}(\%)
\end{aligned}
$$

Fig. 10. Evaluation results of seven-day forecasts from March 25, 2009 to March 31, 2009. (a), (b) and (c) Variation of simulated variables (maximum and minimum temperature, $\mathrm{RH}$, wind speed and precipitation with actual data). (d) RMSE variations between stations.

due to the dropping actual minimum temperatures after March 27, 2009. The model's systematic bias to underestimate high temperatures and to overestimate low temperatures is very evident in this case. The RH plot (Fig. 10b) shows that the simulated values closely follow the pattern of observed values. However, the model mostly underpredicted RH. Wind speed, in general, is overestimated by the modified run (Fig. 10b) due to the unresolved decoupling between different layers of the model and radiative cooling. The modified run followed the observed rainfall patterns but underpredicted the amount of rainfall (Fig. 10c) for the simulation period. The forecast performed consistently across the lead times with an average RMSE of $2.5^{\circ} \mathrm{C}$ for maximum temperatures, $3{ }^{\circ} \mathrm{C}$ for minimum temperatures, $2 \mathrm{~m} \mathrm{~s}^{-1}$ for wind speed, $18 \%$ for $\mathrm{RH}$ and $3.5 \mathrm{~mm}$ for rainfall. The results are in accord with results obtained from earlier studies (Case et al., 2008; Liu et al., 2008; Zhang et al., 2013). 
Across stations, ISRO 346, ISRO 352 and ISRO 354 have large errors while ISRO 344 and ISRO 348 have fewer errors for all the simulated weather variables (Fig. 10d). Interestingly, the stations that had large errors are located in low-lying areas and predominantly have urban and fallow land-uses, while the stations with fewer errors belong to upland agricultural zones. This behavior reveals that modified datasets are useful for realistic micrometeorological weather simulations for extended time periods in vegetated areas. The significant errors in urban and fallow land uses proved that the adjusted datasets (LULC, LAI and DEM) alone are insufficient to capture the entire weather variability in those regions.

\section{Conclusion and future scope}

Results demonstrate an explicit influence of the initial land boundary conditions (e.g., land cover, terrain and LAI) on micrometeorological weather forecasts, especially surface temperature and humidity. Several cases of simulations were attempted to study the varied impact of these variables on a calm day, a rainy day and for an extended time-period. Overall, improvement factors in the range $15-30 \%$ are observed in the quality of the short-term prediction of micro-meteorological elements like 2-m surface temperature, $\mathrm{RH}$, wind speed and solar radiation. Furthermore, the study has illustrated that selecting an optimum resolution and the interpolation methods applied while representing boundary conditions at model resolution are vital to improve the mesoscale model performance. Advanced interpolation techniques used in this study helped in preserving critical land-uses at the model's resolution, which is usually lost while upscaling datasets. The modified run performed consistently well for time scales extending from $12 \mathrm{~h}$ to seven days, which shows that the model ingested the modified datasets without experiencing any shock. Thus, such methodology is feasible for forecasting micrometeorological weather at different spatial and temporal scales. The modification of land state parameters had a higher influence on near-surface temperature, $\mathrm{RH}$ and solar radiation simulations. However, significant overestimation of wind speed is still noticed in the modified run, which demands further experimental study. The model outperformed the control run and simulated near-surface weather exceptionally well in vegetated areas. Realistic simulations are facilitated with the increase (decrease) in canopy evapotranspiration (soil evaporation) due to the update of LULC, LAI and DEM in these areas (Tian et al., 2004). As the representation of vegetation is resolved, most of the surface fluxes are determined by canopy physics rather than the bare soil physics formulation, which leads to discrepancies (biases) in weather simulations ( $\mathrm{RH}$ and minimum temperature) in the region (Yang et al., 1994; Mitchell et al., 2002; Kurkowski et al., 2003). The biases are more prominent in fallow/barren lands where the contribution of soil evaporation on sensible heat flux simulation is high. Thus, soil moisture ingestion/assimilation in the limited-area model becomes vital. Future work would involve ingesting the vegetation fraction and soil moisture inputs along with assimilation of real-time observational data from high-frequency meteorological satellites for improving micrometeorological weather forecasts.

\section{Acknowledgments}

Authors express sincere thanks to the director of the IIRS for the motivation, encouragement and facilities to perform research on weather modeling. Special thanks to Dr. R. Jaganathan, professor of agronomy in the Agro-Climatic Research Centre, Tamilnadu Agricultural University, India, for technical guidance on the WRF model. Authors also wish to thank various individuals and organizations, such as the director of the Space Application Centre (India); the director of the National Remote Sensing Centre (India), and USGS-EROS Center (USA), for providing easy access to in-situ weather data, land cover and biophysical databases.

\section{References}

Beljaars A.C.M., Brown A.R. and Wood N., 2004. A new parameterization of turbulent orographic form drag. Quart. J. Roy. Meteorol. Soc.130, 1327-1347.

DOI: 10.1256/qj.03.73

Biswadip G., 2014. IRS-P6 AWiFS derived gridded land use/land cover data compatible to mesoscale models (MM5 and WRF) over Indian region. NRSC Technical Document, NRSC-ECSA-ACSG-OCT-2014-TR-651.

Case J.L., Crosson W.L., Kumar S.V., Lapneta W.M. and Peters-Lidard C.D., 2008. Impacts of high-resolution land surface initialization on regional sensible weather forecasts from the WRF Model. J. Hydrometeorol. 9, 1246-1266. DOI: 10.1175/2008JHM990.1 
Chen F. and Dudhia J., 2001.Coupling an advanced land-surface-hydrology model with the Penn State-NCAR MM5 modelling system. Part I. Model description and implementation. Mon. Weather Rev. 129, 569-585. DOI: 10.1175/1520-0493(2001)129<0569:CAALSH $>2.0 . \mathrm{CO} ; 2$

Crawford T.M., Stensrud D.J., Mora F., Merchant J.W. and Wetzel P.J., 2001.Value of incorporating satellite-derived land cover data in MM5/PLACE for simulating surface temperatures. J. Hydrometeorol. 2, 453-468. DOI: $10.1175 / 1525-7541(2001) 002<0453$ :VOIS$\mathrm{DL}>2.0 . \mathrm{CO} ; 2$

Dudhia J., 1989. Numerical study of convection observed during the winter monsoon experiment using a mesoscale two-dimensional model. J. Atmos. Sci. 46, 3077-3107. DOI: 10.1175/1520-0469(1989)046<3077:NSOCOD $>2.0 . \mathrm{CO} ; 2$

Eltahir E.A.B., 1998. A soil moisture-rainfall feedback mechanism. 1. Theory and observations. Water Resour. Res. 34, 765-776. DOI: 10.1029/97WR03499

Flaounas E., Bastin S., and Janicot S., 2010. Regional climate modelling of the 2006 West African monsoon: Sensitivity to convection and planetary boundary layer parameterization using WRF. Clim. Dynam. 36, 10831105. DOI: $10.1007 / \mathrm{s} 00382-010-0785-3$

Ge J., Qi J. and Lofgren B., 2008. Use of vegetation properties from EOS observations for land-climate modelling in East Africa. J. Geophys. Res.113, D15101.

DOI: 10.1029/2007JD009628

He J.J., Yu Y., Yu L.J., Liu N. and Zhao S.P., 2017. Impacts of uncertainty in land surface information on simulated surface temperature and precipitation over China. Int. J. Climatol. 37, 829-847. DOI: 10.1002/joc.5041

Hong S.Y., Noh Y. and Dudhia J., 2006. A new vertical diffusion package with an explicit treatment of entrainment processes. Mon. Weather Rev. 134, 2318-2341. DOI: 10.1175/MWR3199.1

Jiménez P.A. and Dudhia J., 2012. Improving the representation of resolved and unresolved topographic effects on surface wind in the WRF model. J. Appl. Meteorol. Climatol. 51, 300-316. DOI: $10.1175 / J A M C-D-11-084.1$

Kain J.S., 2004. The Kain-Fritsch convective parameterization: an update. J. Appl. Meteorol. Climatol. 43, 170181. DOI: $10.1175 / 1520-0450(2004) 043<0170$ :TKCPAU $>2.0 . \mathrm{CO} ; 2$

Kumar P., Bhattacharaya B.K. and Pal P.K., 2013. Impact of vegetation fraction from Indian geostationary satel- lite on short-range weather forecast. Agr. Forest Meteorol. 168, 82-92. DOI: 10.1016/j.agrformet.2012.08.009 Kurkowski N.P., Stensrud D.J. and Baldwin M.E., 2003. Assessment of implementing satellite-derived land cover data in the Eta model. Weather Forecast. 18, 404-416.

DOI: $10.1175 / 1520-0434(2003) 18<404$ :AOISDL $>2.0$. $\mathrm{CO} ; 2$

Lee X., Goulden M.L., Hollinger D.Y., Barr A., Black T.A., Bohrer G., Bracho R., Drake B., Goldstein A., Gu L., et al., 2011. Observed increase in local cooling effect of deforestation at higher latitudes. Nature 479, 384-387. DOI: $10.1038 /$ nature 10588

Lin C.Y., Su C.J., Kusaka H., Akimoto Y., Sheng Y.F., Huang J.C. and Hsu H.H., 2016. Impact of an improved WRF urban canopy model on diurnal air temperature simulation over northern Taiwan. Atmos. Chem. Phys., 16, 1809-1822. DOI: 10.5194/acp-16-1809-2016

Lin Y.L., Farley R.D. and Orville H.D., 1983. Bulk parameterization of the snowfield in a cloud model. J. Clim. Appl. Meteorol. 22, 1065-1092.

DOI: $10.1175 / 1520-0450(1983) 022<1065$ :BPOTS$\mathrm{F}>2.0 . \mathrm{CO} ; 2$

Liu Y., Warner T.T., Astling E.G., Bowers J.F., Davis C.A., Halvorson S.F., Rife D.L., Sheu R., Swerdlin S.P. and Xu M., 2008. The operational mesogamma-scale analysis and forecast system of the U.S. Army Test and Evaluation Command. Part II: Interrange comparison of the accuracy of model analyses and forecasts. J. Appl. Meteor. Climatol. 47, 1093-1104.

DOI: 10.1175/2007JAMC1654.1

Loveland T.R., Reed B.C., Brown J.F., Ohlen D.O., Zhu Z., Yang L. and Merchant J.W., 2000. Development of a global land cover characteristics database and IGBP DISCover from 1-km AVHRR data. Int. J. Remote Sens. 21, 1303-1330. DOI: 10.1080/014311600210191

Matsui T., Lakshmi V. and Small E.E., 2005. The effects of satellite-derived vegetation cover variability on simulated land-atmosphere interactions in the NAMS. J. Climate 18, 21-40. DOI: 10.1175/JCLI3254.1

Mitchell K.E., Ek M.B., Lohmann D., Koren V., Schaake J., Duan Q., Grunmann P., Gayno G., Lin Y., Rogers E., Tarpley D. and Peters-Lidard C., 2002. Reducing near-surface cool/moist biases over snowpack and early spring wet soils in NCEP Eta Model forecasts via land surface model upgrades. Preprints, 16th Conference on Hydrology. American Meteorological Society, Orlando, FL. 
Mlawer E.J., Taubman S.J., Brown P.D., Iacono M.J. and Clough S.A., 1997. Radiative transfer for inhomogeneous atmosphere: RRTM, a validated correlated-k model for longwave. J. Geophys. Res. 102, 16663 16682. DOI: 10.1029/97JD00237

Nicholas F.W. and Lewis J.E., 1980. Relationships between aerodynamic roughness and land use and land cover in Baltimore, Maryland. Geological Survey professional paper 1099-C, U.S. Government Printing Office, Washington DC, pp.1-36.

Pandya M.R., Chaudhari K.N., Singh R.P., Sehgal V.K., Bairagi G.D., Sharma V. and Dadhwal V.K., 2003. Leaf area index retrieval using IRS LISS-III sensor data and validation of MODIS LAI product over Madhya Pradesh. Curr. Sci. 85, 1777-1782.

DOI: $10.1109 /$ TGRS.2006.876028

Pienda N., Jobra O., Jorge J. and Baldasanou J.M., 2004. Using NOAAAVHRR and SPOT VGT data to estimate surface parameters: Application to a mesoscale meteorological model. Int. J. Remote Sens. 25, 129-143. DOI: $10.1080 / 0143116031000115201$

Prabha T.V., Hoogenboom G. and Smirnova T.G., 2011. Role of land surface parameterizations on modeling cold-pooling events and low-level jets. Atmos. Res. 99, 147-161. DOI:10.1016/j.atmosres.2010.09.017

Rahman A., Kumar Y., Fazal S. and Bhaskaran S., 2011. Urbanization and quality of urban environment using remote sensing and GIS techniques in East Delhi, India. Journal of Geographic Information System 3, 62-84. DOI: 10.4236/jgis.2011.31005

Ravindranath M., Arhrit R. and Bohra A.K., 2010. Experiment on utilization of AWiFS LU/LC data in WRF mesoscale model. Annual report NMRF/RR/01/2010. National Centre for Medium Range Weather Forecasting, Ministry of Earth Sciences, India.

Segal M. and Arritt R.W., 1992. Non-classical mesoscale circulations caused by surface sensible heat-flux gradients. Bull. Am. Meteorol. Soc. 73, 1593-1604. DOI: 10.1175/1520-0477(1992)073<1593:NMCCBS $>2.0 . C O ; 2$

Sertel E., Robock A. and Ormeci C., 2009. Impacts of land cover data quality on regional climate simulations. Int. J. Climatol. 30, 1905-2128.

DOI: $10.1002 /$ joc. 2036

Skamarock W.C., Klemp J.B., Dudhia J., Gill D.O., Barker D.M., Duda M.G., Huang X.Y. and Powers J.G., 2008. A description of the advanced research WRF version 3. NCAR/TN-475 STR; NCAR technical note. Mesoscale and Microscale Meteorology Division, National Center of Atmospheric Research, 113 pp.

DOI: $10.5065 / \mathrm{D} 68 \mathrm{~S} 4 \mathrm{MVH}$

Srinivas C.V., Nagaraju C., Venkatesan R., Rao K.G. and Venkatraman B., 2011. Impact of satellite derived vegetation and field soil observations on mesoscale atmospheric model simulations over tropical Indian region during PRWONAM. Asian Journal of Geoinformatics 11, 1-23.

Sun X., Holmes H.A., Osibanjo O.O., Sun Y. and Ivey C.E., 2017. Evaluation of surface fluxes in the WRF Model: Case study for farmland in rolling terrain. Atmosphere 8, 197. DOI: 10.3390/atmos8100197

Tian Y., Dickison R.E., Zhou L. and Shaikh M., 2004. Impacts of new land boundary conditions from moderate resolution imaging spectroradiometer (MODIS) data on the climatology of land surface variables. J. Geophys. Res. 109, D20115. DOI: 10.1029/2003JD004499

Walker H. and Leone J.M., 1994. The impact of elevation data representation on nocturnal drainage wind simulations. Proceedings of the Sixth Conference on Mesoscale Processes. American Meteorological Society, 544-547. DOI: 10.2172/10139554

Walker H., Leone J.M. and Kim J., 1996. The effects of elevation data representation on mesoscale atmospheric model simulations. Third International Conference on Integrating GIS and Environmental Modelling. Santa Fe, NM.

Xue Y., Janjic Z., Dudhia J., Vasic R. and de Sales F., 2014. A review on regional dynamical downscaling in intraseasonal to seasonal simulation/prediction and major factors that affect downscaling ability. Atmos Res. 147-148, 68-85.

DOI: $10.1016 /$ j.atmosres.2014.05.001

Yang R., Fennessy M.J. and Shukla J., 1994. The influence of initial soil wetness on medium-range surface weather forecasts. Mon. Wea. Rev. 122, 471-485. DOI: 10.1175/1520-0493(1994)122<0471:TIOISW $>2.0 . \mathrm{CO} ; 2$

Yuan H., Y Dai., Xiao Z., Ji D. and Shanguaan W., 2011. Reprocessing the MODIS leaf area index products for land surface and climate modelling. Proc. Spie. 115, 1171-1187. DOI: 10.1016/j.rse.2011.01.001

Zhang H., Pu Z. and Zhang X., 2013. Examination of errors in near-surface temperature and wind from WRF numerical simulations in regions of complex terrain. Weather Forecast. 28, 893-914.

DOI: 10.1175/Waf-D-12-00109.1 